\title{
The Hypospadias Phenotype With A Distal Meatus In The Presence Of Distal Penile Penoscrotal Angle Fixation
}

\section{Yuenshan Sammi Wong Kristine Kit Yi Pang Yuk Him Tam}

Division of Paediatric Surgery and Paediatric Urology, Department of Surgery, Prince of Wales Hospital, The Chinese University of Hong Kong, Shatin, NT, Hong Kong, People's Republic of China
Correspondence: Yuk Him Tam Division of Paediatric Surgery \& Paediatric Urology, Department of Surgery, Prince of Wales Hospital, Shatin, NT, Hong Kong, People's Republic of China

Tel +852-35052953

Fax +852-26377974

Email pyhtam@surgery.cuhk.edu.hk
This article was published in the following Dove Press journal: Research and Reports in Urology

\begin{abstract}
Objective: Hypospadias patients may present with the phenotype that features the migration of scrotum to distal penile shaft below a coronal/subcoronal meatus. Patients with this phenotype differ widely in the severity of the hypospadias and the complexity of the surgical repair. We aimed to investigate the operative findings and the outcomes of consecutive patients who presented with this phenotype.
\end{abstract}

Methods: We retrospectively reviewed the medical charts of 31 consecutive patients who underwent hypospadias repairs from January 2014 to May 2017, and the hypospadias was characterized by i) the external urethral meatus at coronal/subcoronal region, ii) scrotal skin encroaching distally resulting in fixation of penoscrotal angle at distal penile shaft, and iii) urethral plate below the glans on penile shaft invisible or barely visible.

Results: The median age at the time of surgery was 15.5 months (10-63). The division of corpus spongiosum was noted at distal penile shaft $(\mathrm{n}=2 ; 6.5 \%)$, mid-shaft $(\mathrm{n}=5 ; 16.1 \%)$ and proximal location $(\mathrm{n}=24 ; 77.4 \%)$. The median ventral curvature before degloving was 45 degrees $(10-90)$. Twenty-eight and 3 patients underwent tubularized incised plate and 2-stage preputial flap repairs, respectively. Twenty-nine of 31 patients required cutback of the hypoplastic urethra. At the time of urethroplasty, 2 (6.5\%), 7 (22.6\%) and 22(70.9\%) patients underwent distal, midshaft and proximal repairs, respectively. At a median follow-up of 30 months (14-50), $6(19.4 \%)$ patients developed one or more complications (fistula $=3$; meatal stenosis $=5$ ).

Conclusion: Patients affected by this particular phenotype likely require non-distal hypospadias repair with possibly higher complication rate and should be treated by surgeons with expertise in complex hypospadias repair.

Keywords: hypospadias, division of corpus spongiosum, distal penile penoscrotal angle fixation

\section{Introduction}

Traditionally, hypospadias has been classified by the external meatal location and in majority of cases the meatus is distally located. ${ }^{1}$ Such classification does not take into account the degree of ventral curvature and the surgical approach required. However, it has long been realized by hypospadias surgeons that the external meatal location does not consistently reflect the severity of the hypospadias defect and the complexity of surgical repair required..$^{2-4}$ The potential pitfall of preoperative assessment concerns especially those cases with apparently distal meatal location but turn out to be more complicated intraoperatively and require more complex repair. $^{5}$ 
Previous studies have focused on surgical techniques and outcomes after hypospadias surgery in which the broad categorization into distal and proximal repair is generally accepted. ${ }^{6-8}$ There are few reports on specific phenotypes of hypospadias. In clinical practice, hypospadias surgeons sometimes encounter hypospadias with encroachment of the scrotum to distal penile shaft below a coronal/subcoronal meatus. ${ }^{9}$ Such anatomical variant is highly variable in the operative findings, and the surgical repair may vary from distal to proximal repair. ${ }^{9}$ Confusion also exists in defining the external meatal location in preoperative assessment as the position can be described to be coronal/subcoronal if glans is used as the reference, or penoscrotal if the scrotum is the reference. ${ }^{2}$

Since the beginning of 2014, we had identified prospectively patients who presented with the hypospadias phenotype that featured penoscrotal angle fixation at distal penile shaft just below a coronal/subcoronal urethral meatus. In this study, we reported the operative findings and the outcomes of 31 consecutive children with such phenotype. We hypothesized that children with this hypospadias phenotype more likely required non-distal type of hypospadias repairs.

\section{Methods}

\section{Patients}

We retrospectively reviewed the medical charts of 31 consecutive children who underwent hypospadias repairs from January 2014 to May 2017. The patients shared the following phenotypic features in their preoperative assessment: i) the external urethral meatus at coronal/subcoronal position; ii) scrotal skin encroaching distally resulting in penoscrotal angle fixation at distal penile shaft, with paucity of ventral penile shaft skin between the meatus and scrotum; and iii) urethral plate below the glans on penile shaft invisible or barely visible (Figure 1).

Data collected were age at the time of surgery, degree of ventral curvature before and after penile degloving, location of the division of corpus spongiosum, cutback of hypoplastic urethra, surgical techniques of urethroplasty and correction of ventral curvature, length of hypospadias repairs (distal/mid-shaft/proximal), complications, and length of follow-up.

This study was approved by the Joint CUHK-PWH Clinical Research Ethics Committee, and the informed consent was waived given the retrospective nature of the study without reporting any personal identifiable information.

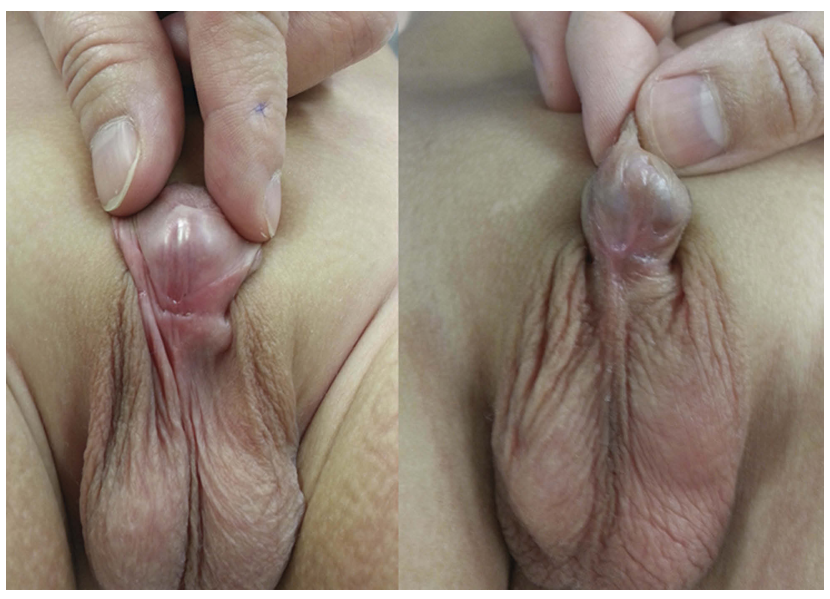

Figure I The hypospadias phenotype of a coronal/subcoronal meatus in the presence of distal penile penoscrotal angle fixation.

\section{Intraoperative Anatomical Considerations}

In all cases we started with penile degloving. Ventral dissection was performed cautiously to take down the distally migrated scrotum until proximal dissection was adequate to release the scrotum to its normal penoscrotal junction. The level of the division of corpus spongiosum was identified, the degree of remaining ventral curvature was estimated, and the quality of the hypoplastic urethra between the external urethral meatus and division of corpus spongiosum was assessed.

Hypoplastic urethra was cutback from the external meatus if the hypoplastic urethra was perforated during degloving, thinned out without subepithelial tissue, and/or narrowed with significant gripping on a Fr 8 catheter. The hypoplastic urethra was not necessarily cutback to exactly the division of corpus spongiosum. The cutback stopped at where the hypoplastic urethra was considered to be of good quality and adequate lumen retained by approximating the spongiosum tissue on the two lateral sides over it.

Residual ventral curvature $<30$ degrees after adequate degloving was corrected by dorsal midline plication followed by 1-stage hypospadias repair. Patients with more severe ventral curvature underwent transection of the urethral plate and mobilization of the transected urethral plate/corpus spongiosum from the corpora cavernosa with or without additional dorsal midline plication. Patients requiring transection of urethral plate underwent 2 -stage repairs. All the procedures were performed by or under the supervision of the senior author.

Based on the meatal location at the time of urethroplasty after cutback of hypoplastic urethra if any, the 
hypospadias repair was defined to be distal, mid-shaft, or proximal. Urethral catheter was left in place for free drainage for 1-2 weeks after surgery depending on the length of urethroplasty. Patients were followed up at 2-4 weeks, 3 months, 6-9 months, and then yearly after surgery.

\section{Results}

Table 1 summarizes the findings of the 31 patients. The median age at the time of surgery was 15.5 months (range 10-63). After degloving, the division of corpus spongiosum was noted at distal penile shaft $(\mathrm{n}=2 ; 6.5 \%)$, mid-shaft $(\mathrm{n}=5 ; 16.1 \%)$ and proximal location $(\mathrm{n}=24 ; 77.4 \%)$.

Tubularized incised plate (TIP) and 2-stage preputial flap repairs were performed in 28 and 3 patients, respectively. The surgical techniques followed the principles described in the literature ${ }^{10,11}$ with our modification on the choice of barrier flaps. ${ }^{12}$ The median ventral curvature before degloving was 45 degrees (range 10-90). Twelve patients had a full correction of ventral curvature after degloving while 16 required additional dorsal midline plication for the remaining ventral curvature $<30$ degrees. The 28 patients who had their urethral plate preserved underwent TIP (Figure 2). Three patients had $>45$ degrees ventral curvature remaining despite adequate degloving and subsequently underwent 2 -stage repair with transection of the urethral plate plus dorsal midline plication (Figure 3).

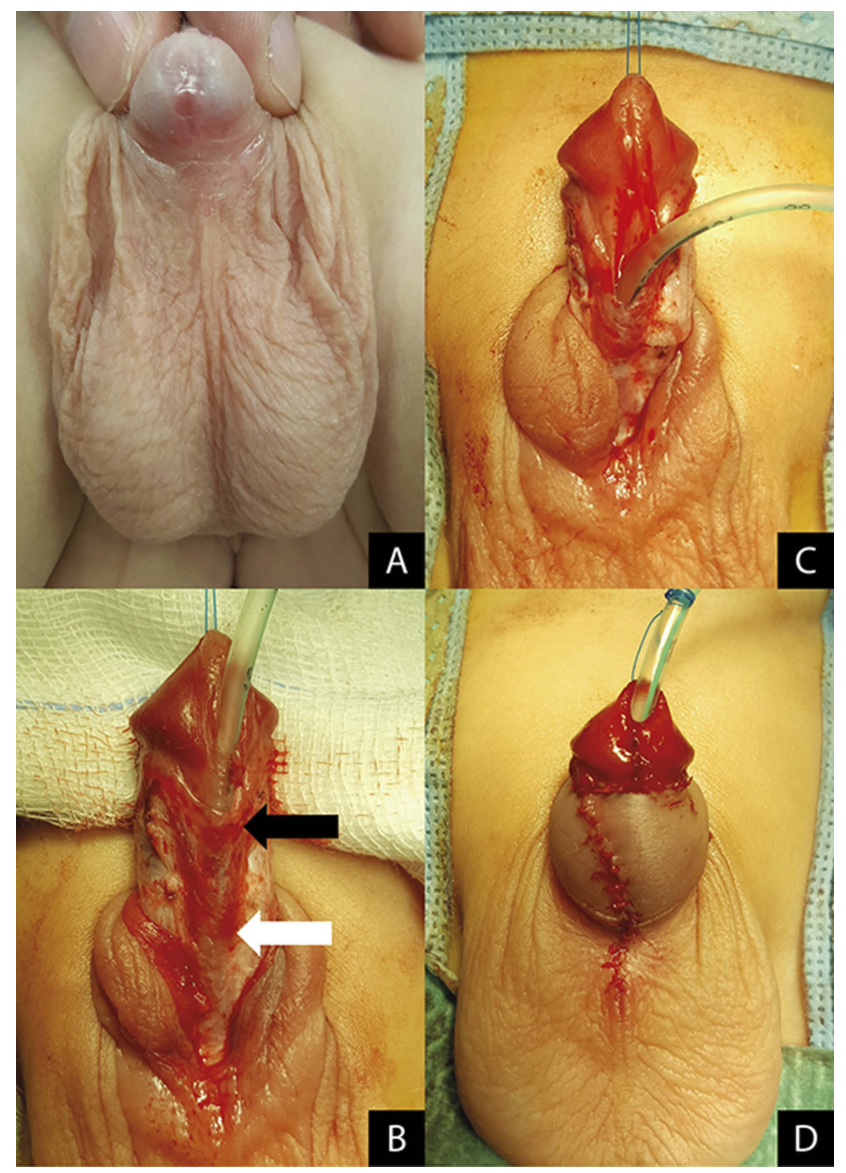

Figure 2 A patient who underwent TIP. (A) Immediate before surgery. (B) After penile degloving; original position of the penoscrotal angle (black arrow); division of corpus spongiosum (white arrow). (C) After cutback of the hypoplastic urethra. (D) Immediately after surgery.

Table I Summary Of The Findings Of The 3I Patients

\begin{tabular}{|l|l|l|l|}
\hline Division Of Corpus Spongiosum & Distal N=2 & Mid-Shaft N=5 & Proximal N=24 \\
\hline $\begin{array}{l}\text { Techniques to correct ventral curvature } \\
\text { I. Degloving alone } \\
\text { 2. Degloving + Midline dorsal plication } \\
\text { 3. Degloving + Midline dorsal plication + Transection of urethral plate }\end{array}$ & $2 / 2$ & $3 / 5$ & $7 / 24$ \\
\hline Cutback of hypoplastic urethra & $0 / 2$ & $3 / 24$ \\
\hline $\begin{array}{l}\text { Techniques of urethroplasty } \\
\text { I. Tubularized incised plate } \\
\text { 2. Staged preputial flap }\end{array}$ & $2 / 24$ & $24 / 24$ \\
\hline $\begin{array}{l}\text { Extent of hypospadias repair } \\
\text { I. Distal } \\
\text { 2. Mid-shaft } \\
\text { 3. Proximal }\end{array}$ & & $5 / 5$ & $21 / 24$ \\
\hline $\begin{array}{l}\text { Complications } \\
\text { I. Meatal stenosis } \\
\text { 2. Urethocutaneous fistula } \\
\text { 3. Meatal stenosis + urethrocutaneous fistula }\end{array}$ & $2 / 2$ & $3 / 24$ \\
\hline
\end{tabular}




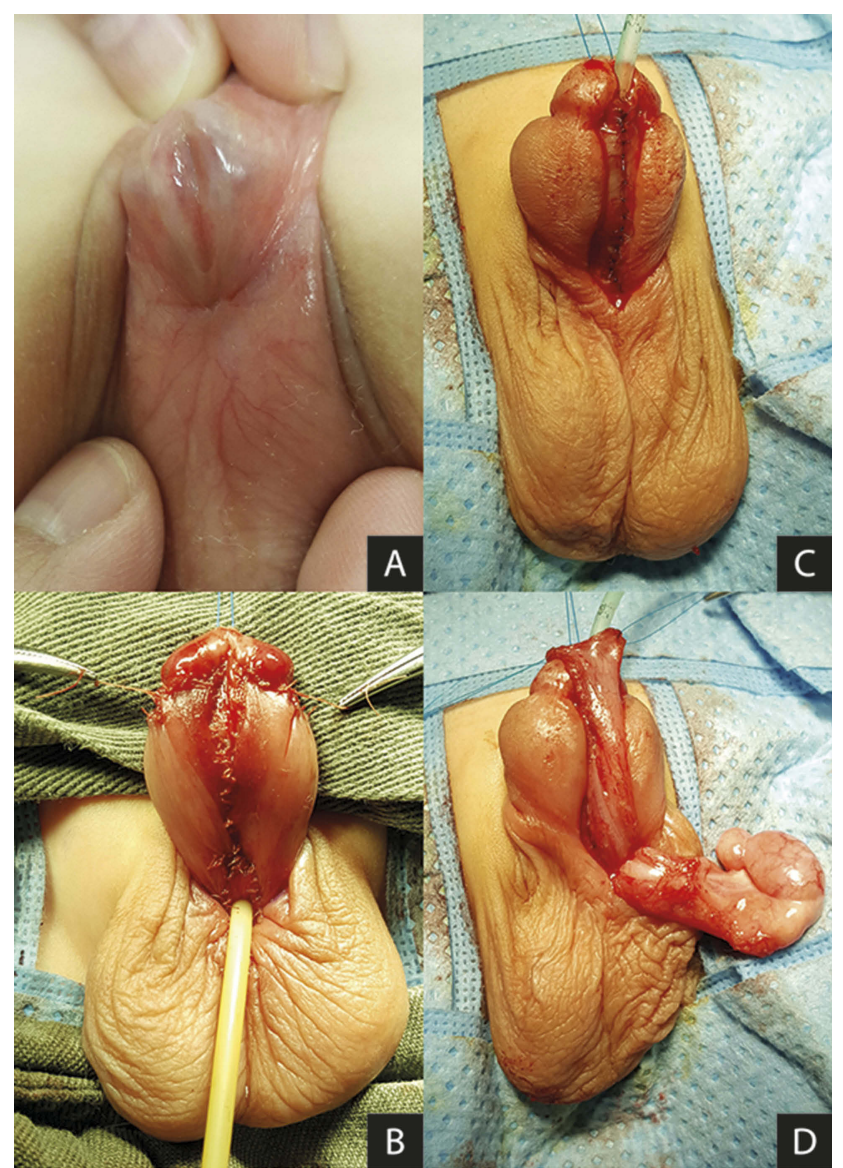

Figure 3 A patient who underwent 2-stage preputial flap repair. (A) Immediately before surgery. (B) Immediately after the Ist stage. (C) Completion of urethroplasty in the 2nd stage. (D) Harvest of tunica vaginalis flap to cover the neourethra.

All but two patients with the division of corpus spongiosum at distal shaft had cutback of the hypoplastic urethra from external meatus. Based on the meatal location at the time of urethroplasty, 2 (6.5\%), 7 (22.6\%) and 22 $(70.9 \%)$ patients underwent distal, mid-shaft and proximal repairs, respectively.

At a median follow-up of 30 months (range 14-50), 6 (19.4\%) patients developed one or more complications (fistula, $\mathrm{n}=3$; meatal stenosis, $\mathrm{n}=5$ ). All 6 patients had non-distal repair of hypospadias.

\section{Discussion}

The anatomical anomaly in hypospadias is defined by the hypoplasia of the ventral tissues beyond the division of the corpus spongiosum of penis. ${ }^{4}$ While evaluation should be done both pre- and intra-operatively, the exact extent of the anatomical defect may only be ascertained at the time of surgery when the penis is fully degloved. ${ }^{9}$ For practical reasons, the preoperative assessment will facilitate the consenting process and preparation of the operative settings if it can suggest reliable clues of the severity of the hypospadias and the surgical techniques likely required. In clinical practice, most of the distal or proximal hypospadias appear to be obvious in preoperative assessment. However, the phenotype being investigated in the present study is a tricky anatomical variant with high unpredictability.

The present study reported a series of consecutive patients who were characterized by the fixation of penoscrotal angle at distal penile shaft just below a coronal/ subcoronal meatus. This variant can be distinguished from the majority of patients having coronal/subcoronal meatus with an adequate length of healthy shaft skin on the ventrum between the meatus and the scrotum. For such patients, a straightforward distal repair with high success rate should be expected. Our patients in this study can also be distinguished from those having obviously proximal hypospadias with a visible urethral plate on the penile shaft beyond the proximally located meatus. Uncommonly proximal hypospadias may present with a distal meatus while the hypoplastic urethra is covered by very thin ventral shaft skin. Such anatomical variant should also be distinguished from the phenotype being investigated in this study.

When performing the ventral dissection in our patients, we consistently encountered significant tethering of scrotal dartos on the hypoplastic urethra, at the division of corpus spongiosum and on the lateral sides of the two divided limbs of the spongiosum. The most unpredictable element was the degree of hypoplasia of the ventral tissues and its proximal extent, which had been masked by the scrotal skin prior to penile degloving. The location of the division of corpus spongiosum and the degree of hypoplasia between it and the external meatus determines two critical issues. Firstly how much hypoplastic urethra needs to be abandoned and the length of the urethroplasty that needs to be fashioned. Secondly, how much ventral curvature can be corrected by ventral dissection and taking down the distally migrated scrotum to its normal penoscrotal position, and if additional midline dorsal plication or even transection of the urethral plate is deemed necessary.

Despite the distal location of the external meatus, the division of corpus spongiosum was located distally in less than $10 \%$ of our patients. In contrast, over $70 \%$ of the patients had the division of corpus spongiosum located at proximal positions further below the penoscrotal angle before degloving. In retrospect, this finding should not be unexpected as the scrotal encroachment to distal penile shaft may just be another way to reflect the underdevelopment or even absent 
development of the ventral shaft skin which is a feature in proximal hypospadias.

All the 29 patients with the division of corpus spongiosum at non-distal positions needed cut-back of the hypoplastic urethra. We agree with others that hypoplastic urethra does not necessarily require cutback in every case of hypospadias repair. ${ }^{5}$ However, most patients in this study had varying length of unhealthy hypoplastic urethra that we thought should not be preserved. We do not necessarily cut back the hypoplastic urethra to exactly the division of corpus spongiosum. In some cases we found that the last $5-6 \mathrm{~mm}$ of the urethra distal to the division of corpus spongiosum had an adequate lumen and good quality to preserve by simply approximating the divided spongiosum tissues over it. We used the criterion of free passage of Fr 8 catheter to define adequate lumen of the hypoplastic urethra and to determine if cutback was necessary or if it was enough. While such assessment is based on the qualitative and subjective judgement of the operating surgeon and its application may be debatable, we think this is a practical and reasonable measure to prevent creating a narrowed urethra given Fr 8 catheter as the urethral stent is commonly used in hypospadias repairs.

Half of our patients had their ventral curvature corrected after penile degloving and untethering the attachments of the distally migrated scrotum to return the scrotum to the normal penoscrotal junction. Our finding appears to be in agreement with the general impression about the ventral curvature in proximal hypospadias that about half of the patients do not require further correction after degloving. ${ }^{9}$ Mouriquand and Mure have reported that penile degloving alone straightens the penis in $80 \%$ of all hypospadias repairs, ${ }^{4}$ while in the series of Snodgrass and Prieto, the ventral curvature in $50 \%$ of proximal hypospadias was corrected by penile degloving with or without additional dorsal plication. ${ }^{13}$ Three of our patients had severe ventral curvature and required 2-stage repair with transection of the urethral plate. The findings of the present study again demonstrate that there is no place for occasional surgeons or surgeons who claim to be competent only in distal repairs. ${ }^{5,6}$ The presence of the coronal/ subcoronal meatus may be misinterpreted as distal hypospadias with the false expectation of 1-stage straightforward repair. On the contrary, over two-thirds of our patients underwent proximal repairs. Given the unpredictability of the severity of the hypospadias defect prior to surgery, we routinely got the informed consent from parents of the study subjects to the possibility of unplanned 2-stage repair. It cannot be overemphasized that there is no international consensus on the choice of surgical technique in hypospadias repair, particularly in proximal type, and our employed techniques just reflect our preferred options based on our experience.

Recently, studies from major centers have reported complication rates $>50 \%$ after proximal hypospadias repair. $^{11,14,15}$ Meta-analysis of TIP has found $12.2 \%$ re-operation rate after proximal repair in contrast to $4.5 \%$ after distal repair. ${ }^{7}$ Hypospadias surgeons are well aware of the phenotype variations in proximal hypospadias that may influence the choice of surgical techniques and may affect the outcomes as well. ${ }^{14,15}$ Our finding that $19.4 \%$ of patients developed complication appears to be a reasonable reflection of the heterogeneity in the hypospadias severity of these patients with the majority requiring non-distal repairs. Further studies comparing those with and without distal penile penoscrotal angle fixation using similar surgical techniques are warranted to investigate if such anatomical feature carries any prognostic value in the success of hypospadias surgery.

Our study was limited by its relatively small number, lack of objective assessment of the cosmetic and functional outcomes, and the potential bias associated with the subjective judgement of the hypospadias phenotype and the quality of the hypoplastic urethra. The relatively short follow-up may not allow detection of late complications such as recurrent ventral curvature which is a concern particularly after proximal TIP repairs. Intraoperative determination of the degree of ventral curvature may also not be precise. Nevertheless, our study provides evidence of the variability in the anatomical defect and the likelihood of non-distal repair among the patients with the phenotype which features a distal meatus in the presence of penoscrotal angle fixation at the distal penile shaft.

\section{Conclusion}

To predict the complexity of hypospadias repair, it is important in preoperative evaluation to assess the degree of ventral curvature and the position of the penoscrotal angle with respect to the penile shaft and the location of the meatus. Patients affected by the hypospadias phenotype investigated in this study should be managed by surgeons with expertise in complex hypospadias repairs, and the parents should be well informed of the likelihood of higher complication risk. 


\section{Author Contributions}

All authors contributed to data analysis, drafting or revising the article, gave final approval of the version to be published, and agree to be accountable for all aspects of the work.

\section{Disclosure}

All the authors declare that they have no competing interests in this work.

\section{References}

1. Baskin LS. Hypospadias. In: Grosfeld JL, O’Neill JA Jr, Fonkalsrud EW, Coran AG, editors. Pediatric Surgery. Vol. 2, 6th. Philadelphia: Mosby Elsevier;2006:1870-1898.

2. Orkiszewski M. A standardized classification of hypospadias. $J$ Pediatr Urol. 2012;8(4):410-414. doi:10.1016/j.jpurol.2011.08.011

3. Mouriquand PD, Gorduza DB, Noché ME, Targnion A. Long-term outcome of hypospadias surgery: current dilemmas. Curr Opin Urol. 2011;21(6):465-469. doi:10.1097/MOU.0b013e32834a6da3

4. Mouriquand PD, Mure PY. Current concepts in hypospadiology. BJU Int. 2004;93(Suppl 3):26-34. doi:10.1111/j.1464-410X.2004.04706.x

5. Malone P. Commentary to "A standardized classification of hypospadias”. J Pediatr Urol. 2012;8(4):415. doi:10.1016/j.jpurol.2011.08.006

6. Steven L, Cherian A, Yankovic F, Mathur A, Kulkarni M, Cuckow P. Current practice in paediatric hypospadias surgery: a specialist survey. $J$ Pediatr Urol. 2013;9(6 Pt B):1126-1130. doi:10.1016/j.jpurol.2013.04.008
7. Pfistermuller KL, McArdle AJ, Cuckow PM. Meta-analysis of complication rates of the tubularized incised plate (TIP) repair. J Pediatr Urol. 2015;11(2):54-59. doi:10.1016/j.jpurol.2014.12.006

8. Wilkinson DJ, Farrelly P, Kenny SE. Outcomes in distal hypospadias: a systematic review of the mathieu and tubularized incised plate repairs. J Pediatr Urol. 2012;8(3):307-312. doi:10.1016/j.jpurol.20 10.11.008

9. Snodgrass W, Macedo A, Hoebeke P, Mouriquand PD. Hypospadias dilemmas: a round table. J Pediatr Urol. 2011;7(2):145-157. doi:10. 1016/j.jpurol.2010.11.009

10. Snodgrass WT. Snodgrass technique for hypospadias repair. BJU Int. 2005;95(4):683-693. doi:10.1111/j.1464-410X.2005.05384.x

11. McNamara ER, Schaeffer AJ, Logvinenko T, et al. Management of proximal hypospadias with 2 -stage repair: 20 -year experience. $J$ Urol. 2015;194(4):1080-1085. doi:10.1016/j.juro.2015.04.105

12. Tam YH, Pang KK, Wong YS, et al. Improved outcomes after technical modifications in tubularized incised plate urethroplasty for mid-shaft and proximal hypospadias. Pediatr Surg Int. 2016;32 (11):1087-1092. doi:10.1007/s00383-016-3954-6

13. Snodgrass W, Prieto J. Straightening ventral curvature while preserving the urethral plate in proximal hypospadias repair. $J$ Urol. 2009;182(4 Suppl):1720-1725. doi:10.1016/j.juro.2009.02. 084

14. Pippi Salle JL, Sayed S, Salle A, et al. Proximal hypospadias: a persistent challenge. Single institution outcome analysis of three surgical techniques over a 10-year period. J Pediatr Urol. 2016;12 (1):28.e1-e7. doi:10.1016/j.jpurol.2015.06.011

15. Long CJ, Chu DI, Tenney RW, et al. Intermediate-term followup of proximal hypospadias repair reveals high complication rate. J Urol. 2017;197(3 Pt 2):852-858. doi:10.1016/j.juro.2016.11.054

\section{Publish your work in this journal}

Research and Reports in Urology is an international, peer-reviewed, open access journal publishing original research, reports, editorials, reviews and commentaries on all aspects of adult and pediatric urology in the clinic and laboratory including the following topics: Pathology, pathophysiology of urological disease; Investigation and treatment of urological disease; Pharmacology of drugs used for the treatment of urological disease. The manuscript management system is completely online and includes a very quick and fair peer-review system, which is all easy to use. Visit http://www.dovepress.com/ testimonials.php to read real quotes from published authors. 